ص ص[1.7-94]

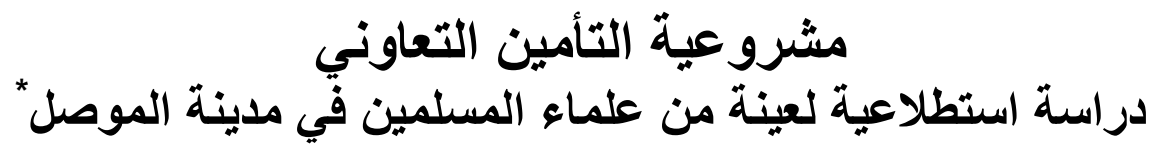

ياسين محمد يونس

دبلوم عالي في الإدارة الصحية و إدارة المستشفيات
الدكتور جرجيس عمير عباس

أستاذ مساعد - قسم إدارة الأعهال

كلية الإدارة و الاقتصاد- جامعة الموصل

Gargesabbas@yahoo.com

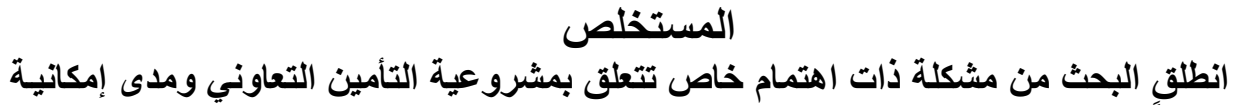

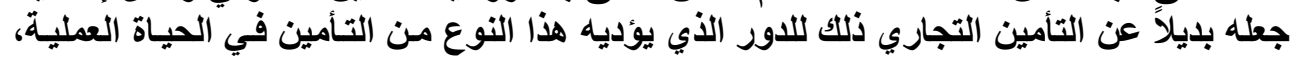

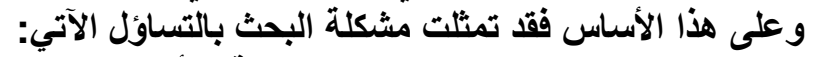

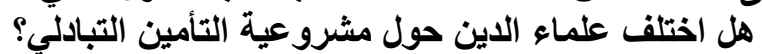

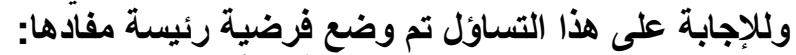

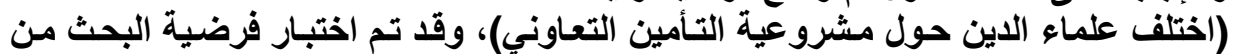

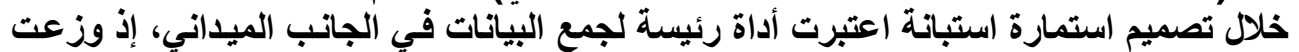

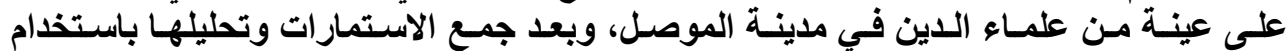

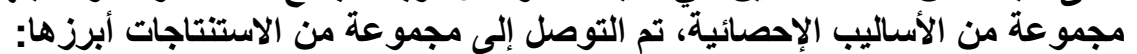

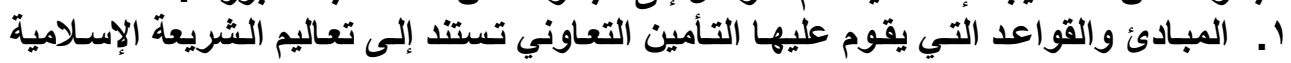
السمحاء. ץ. . يخلو التأمين التعاوني من عيوب عقود التأمين المعروفة كالغزر والجهالة والربا.

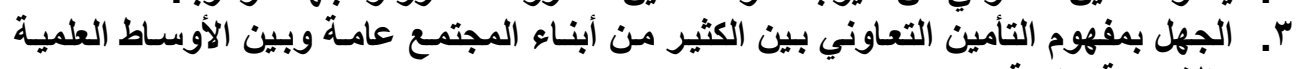
والشرعية خاصة.

$$
\begin{aligned}
& \text { * البحث مستل من رسالة دبلوم عالي الموسوم "مشرو عية التأمين التعاوني در اسة استطلاعية لعينة }
\end{aligned}
$$

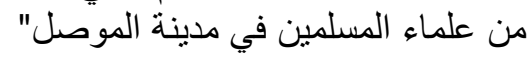

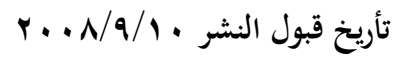

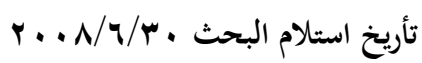




\title{
The Legality of Mutual Insurance A Pilot Study of Clerics in Mosul City
}

\author{
Jarjees O. Abbas (PhD) \\ Assistant Professor \\ Department of Business Administration \\ University of Mosul
}

\author{
Yaseen M. Younis \\ H.D. Health Management
}

\begin{abstract}
The research embarked on a problem of particular concern to the legality of interoperability insurance and the possibility that makes it an alternative to the commercial insurance for the role played by this type of life insurance in the practical life. On this basis, the problem has been embodied in the following: Are religious scholars disagreed on the legality of mutual insurance? The answer of this question was a hypothesis: (Are the religious scholars disagree on the legality of mutual insurance? The hypothesis of the research was done through questionnaire. It has been considered as the key tool of data collection in field distributed on a sample of clerics in Mosul City. The forms have been collected and analyzed in terms of several statistical methods. The study concluded the following:

1. Principles and rules on which the insurance interoperability based on the teachings of the tolerant Islamic Sharia.

2. Free insurance interoperability defects insurance contracts known Kalgrr and obscurantism and usury.

3. Ignorance of the concept of insurance interoperability among many members of the society generally and between the scientific community and legitimacy particular. Islam prohibits other types of insurance.
\end{abstract}

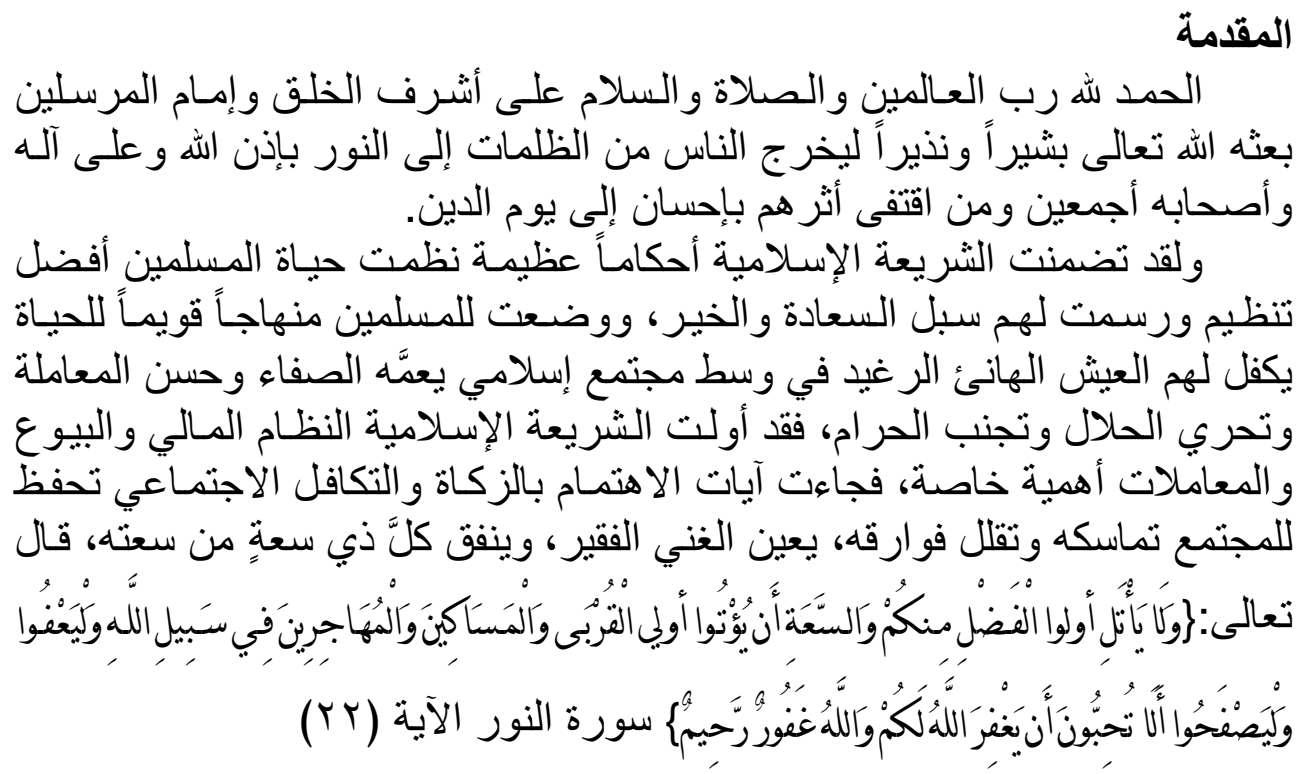




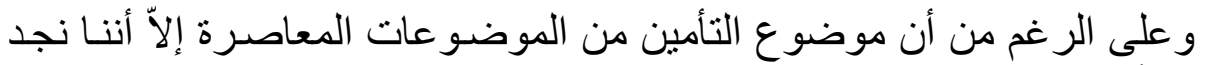

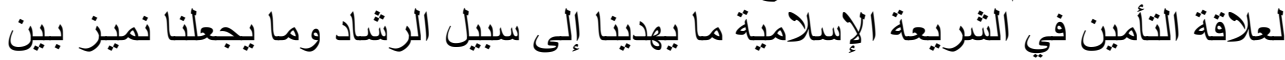

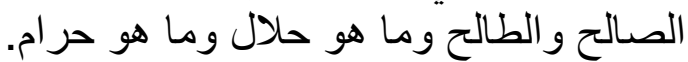

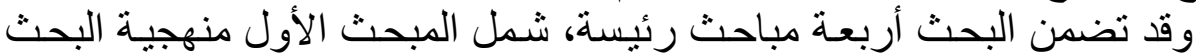

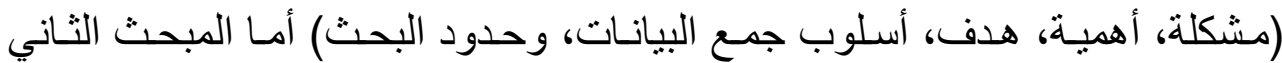

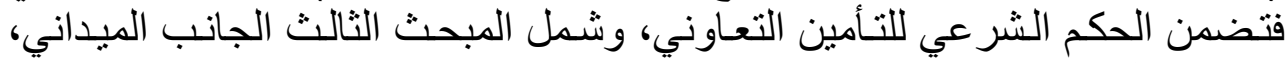
وتضمن المبحث الر ابع الاستتناجات و المقترحات.

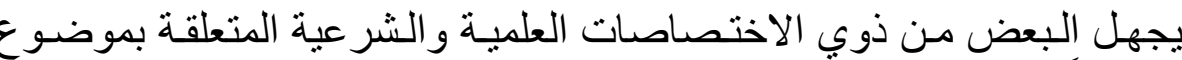

\section{منهجية البحث أولاًا- مشكلة البحث}

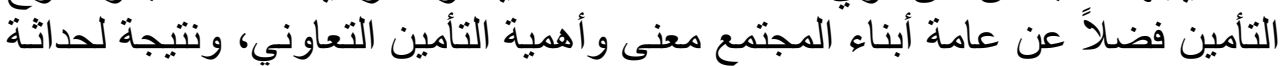

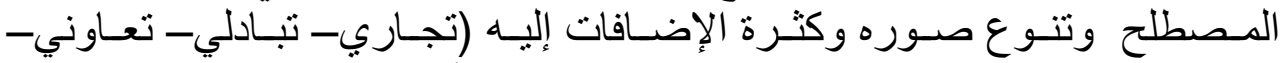

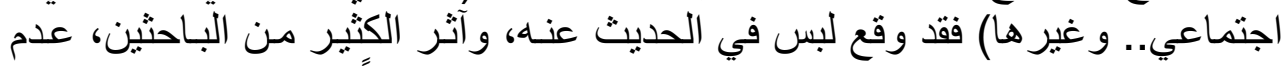

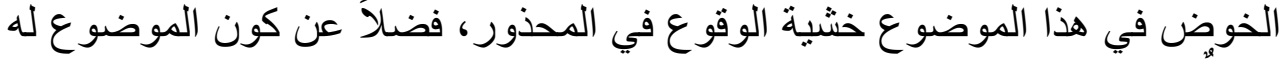

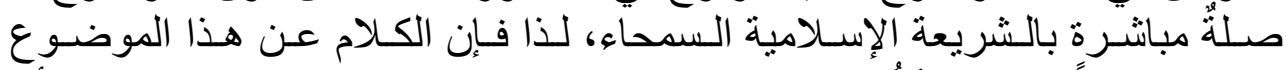

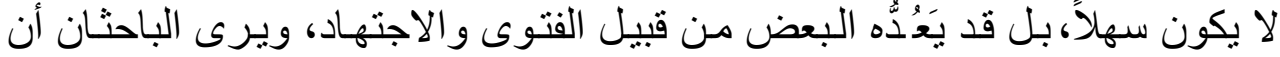

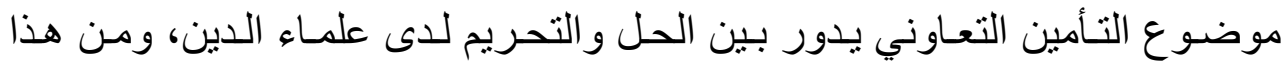

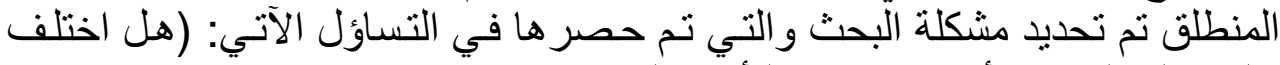
علماء المسلمين بشأن مشروعية التأمين التعاوني)؟

إن موضوع التأمين التعاوني لا يكاد يذكر في بلادنا- في حدود ما اطلعنا عليه-

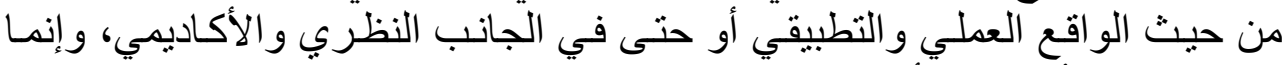

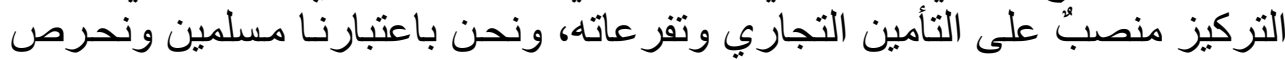

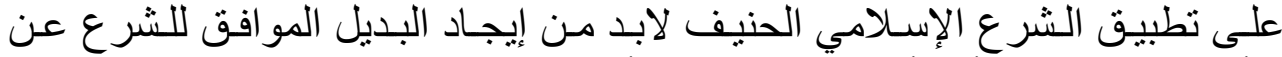

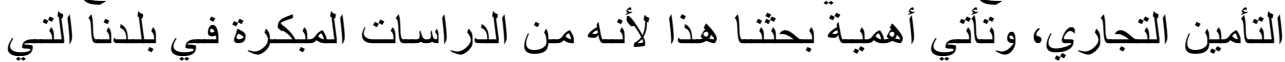

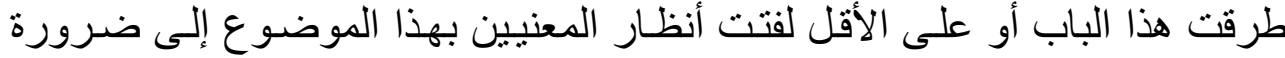

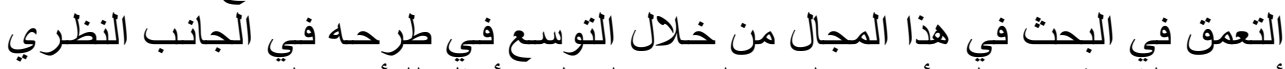
أو محاولة تطبيقه على أرض الو القع ليكون البديل الأمثل للتأمين التجاري.

$$
\text { ثالثاً - ـ أهداف البحث }
$$

يحساول البحث تحقيق مجموعـة من الأهداف ذات العلاقة بموضـوع التـأمين

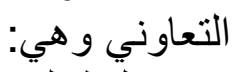

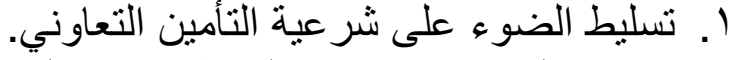

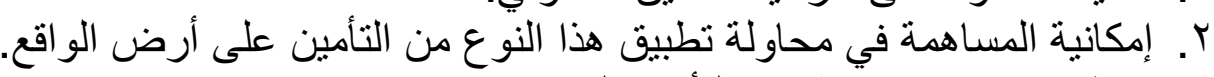
r. إعطاء صورة واضحة عن التأمين التعاوني. 
ع. بيان أوجه الاختلاف و الاتفاق بين التأمين التعاوني و التأمين التجاري.

تمانثيا مع أهداف البحث فقد اعتمد البحث على فرضية رئيسة مفادها:

$$
\text { رابعاً ـ- فرضية البحث }
$$

(هنالك اختلاف بين علماء المسلمين حول مشرو عية التأمين التعاوني)

\section{خامساً- أساليب جمع البيانات}

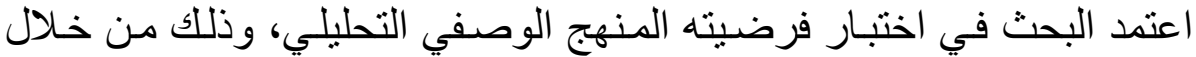

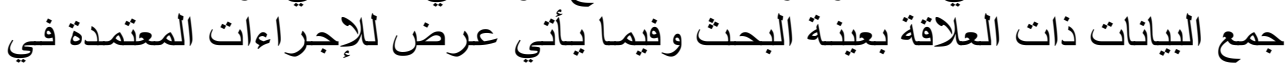

$$
\text { أل الإطار النظري }
$$

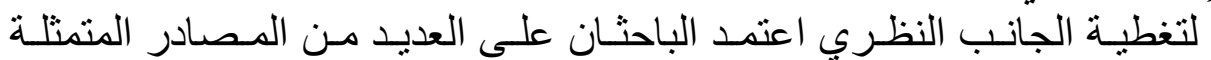

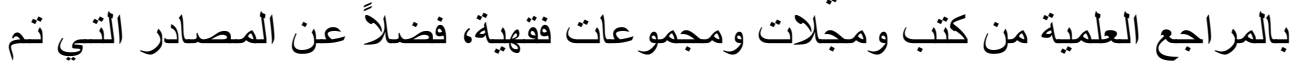
الحصول عليها من الثنبكة الدولية للمعلومات ومئ (الإنترنت).

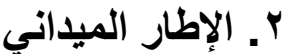

أما فيما يخص الجانب الميداني فقد استخدمت الوسائل الآتية في جمع البيانات:

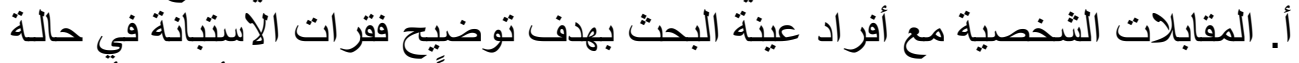

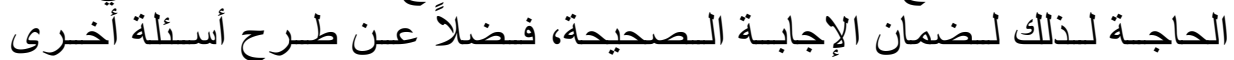

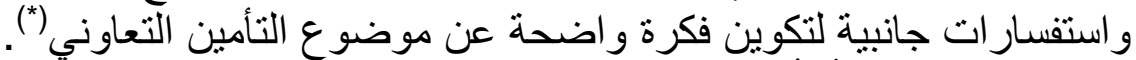

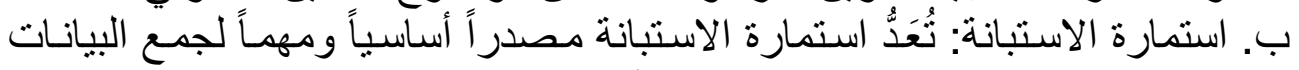

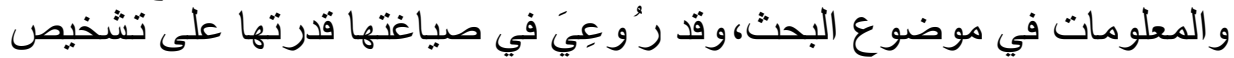

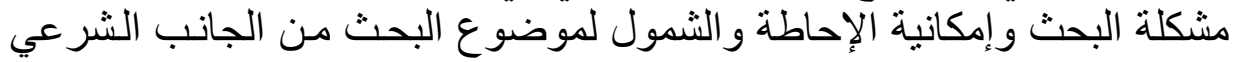

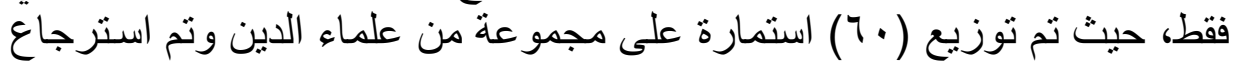

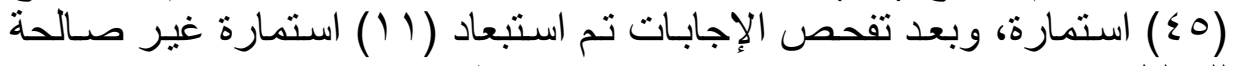
للتحليل الإحصائي، وتم اعتماد (ع ب) استمارة فقط. ج. وصف استمارة الاستبانة تضمنت استمارة الاستبانة جز أين وبحسب الآنئ الآتي:

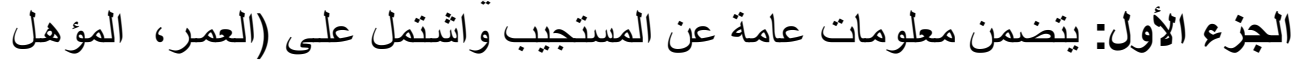

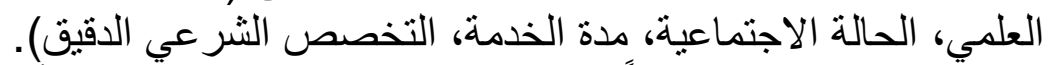

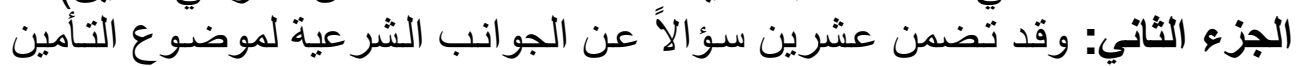

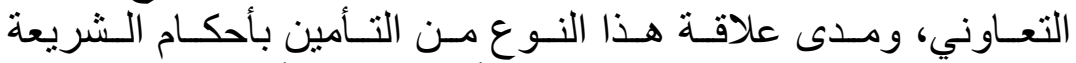

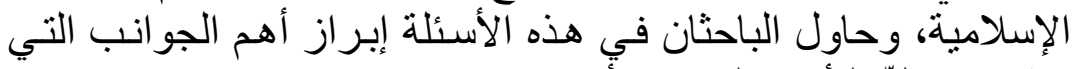

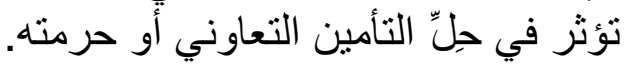

سادساً حدود البحث البرث

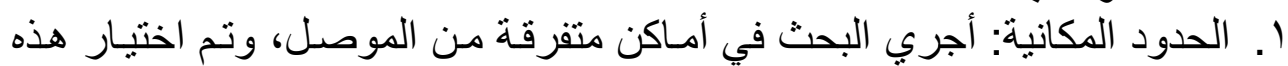
المناطق من أجل شمول أكبر جزء من شريحة أفر اد العينة العنة (عينة عمديـة) منها هذها 
كليات الثريعة، و العلوم الإسلامية في المدينة، و هيئة ور ابطة علماء المسلمين في الموصل، و عدد من المساجد في أحياء متفرقة من من المداء المدينة.

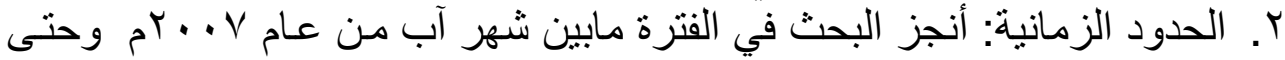

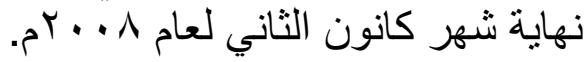

تم الاعتماد على مجمو التيل الإحصائي من الوسيائل و الأدوات الإحصائية لغرض التوصل

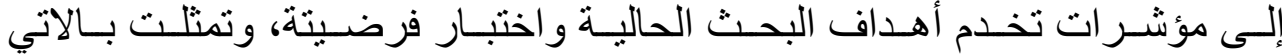
(التكر ارات و النسب المئوية والمتوسطات الحسابية والانحر افات المعيارية).

$$
\text { الحكم الشرعي للتأمين التعاوني }
$$

قبل أن نتناول الحكم الثرعي لأني للتأمين التعاوني و أدلته لابد لنا أن نبين وبصورة

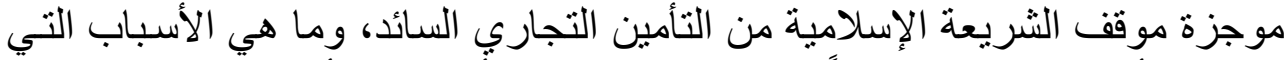

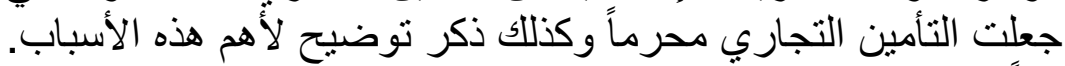

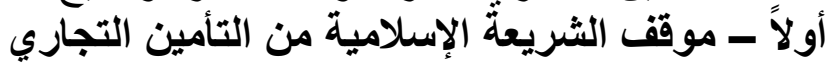

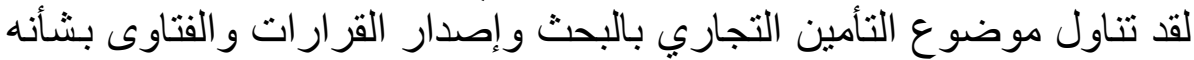
الكثير من الهيئات و المجمعات الفقيهة المعتمدة في العالم الإسلامي، ومن ذلك مالكا أقره

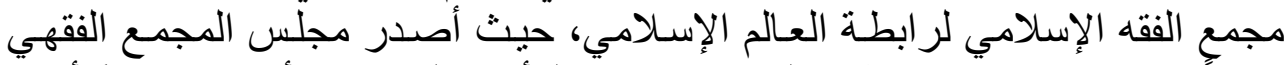

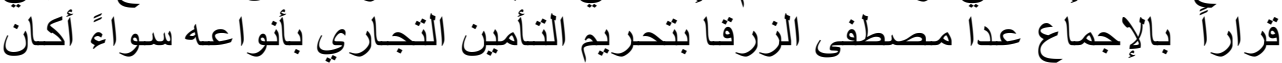

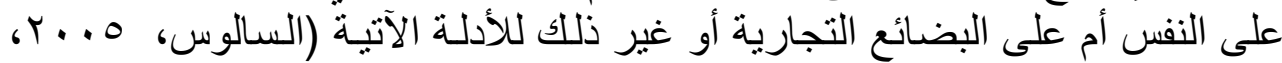

ا . عقد التأمين التجاري من عقود المعاوضات المالية الاحتمالية المشتملة على الغرر

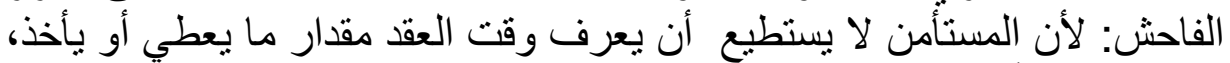

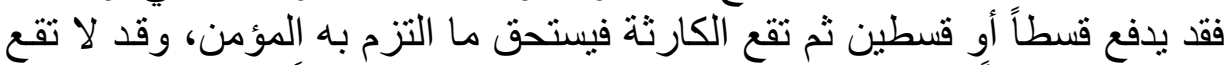

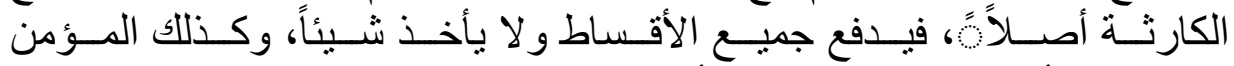

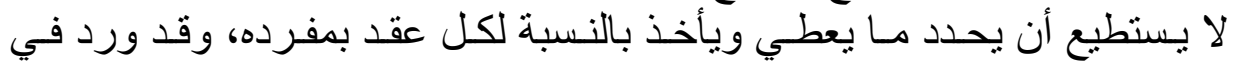

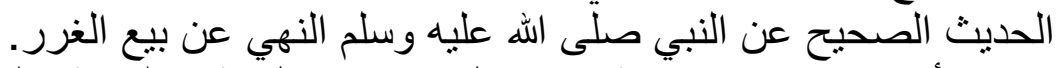

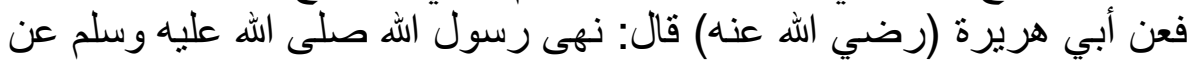

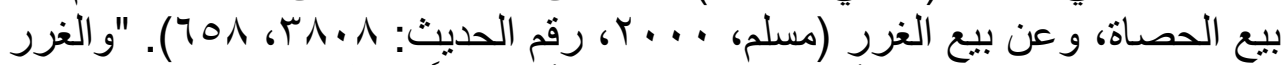

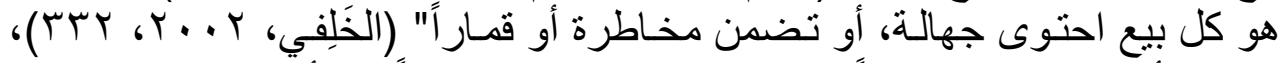

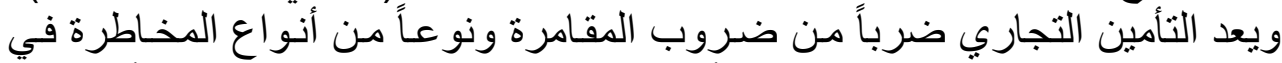

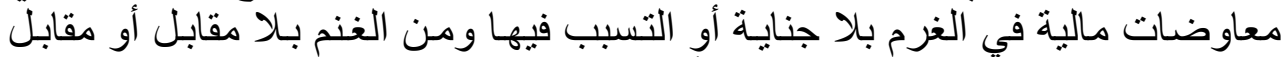

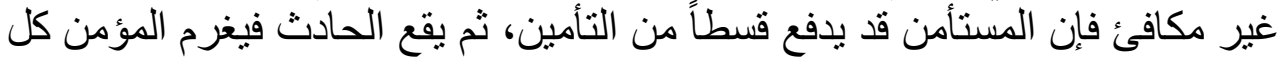

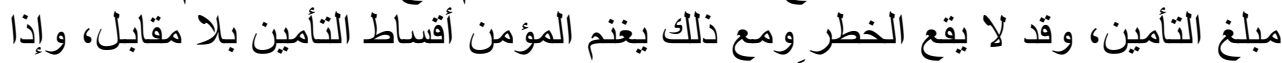

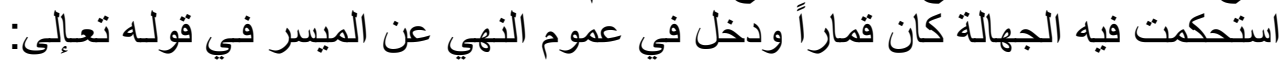




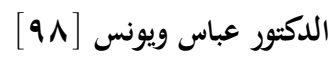

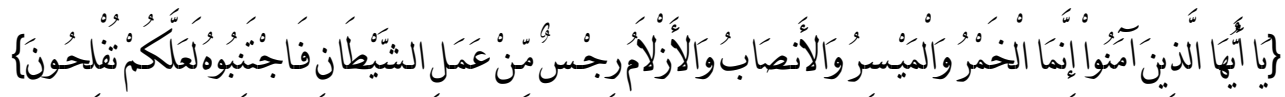
المائدة الآية)(9. (9)

\section{ثانياً المجيزون للتأمين}

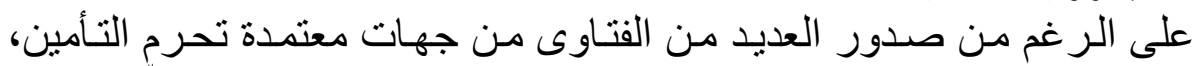

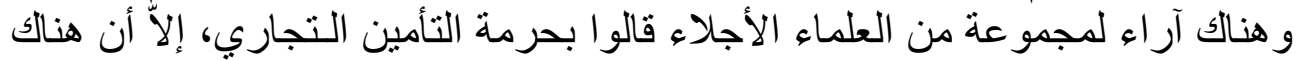

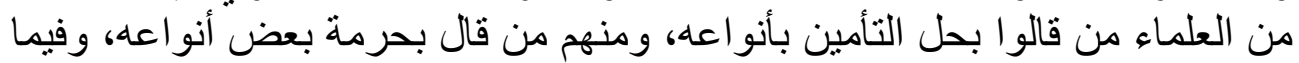

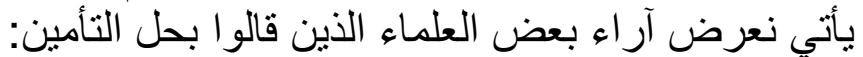

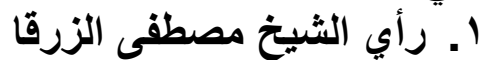

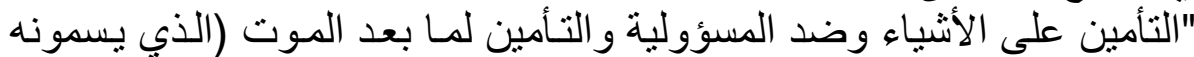

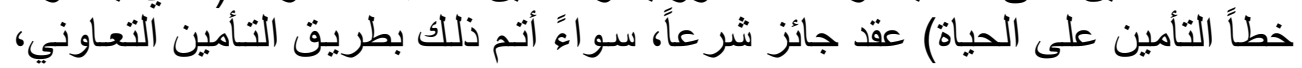

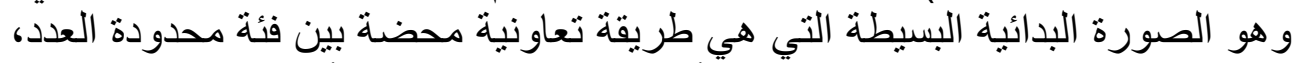

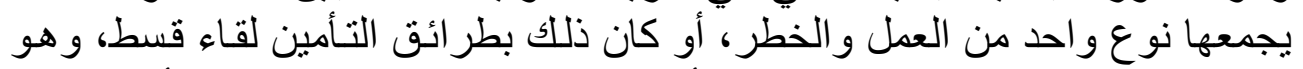

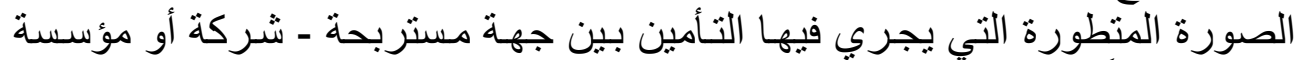

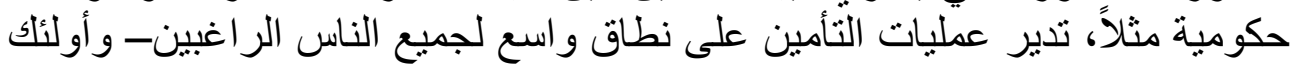

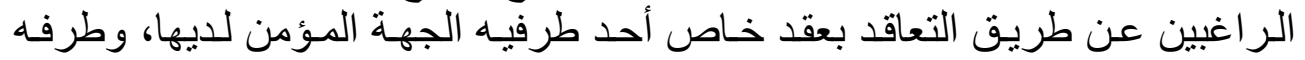

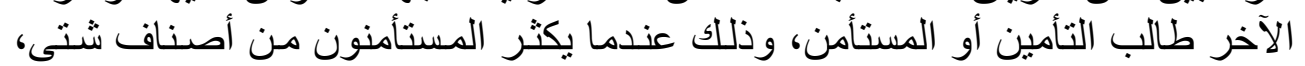

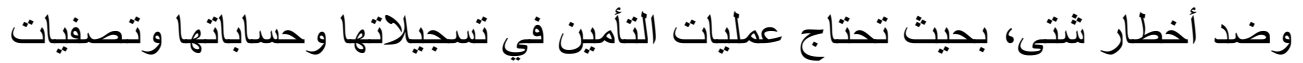

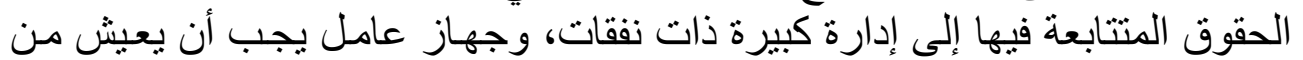

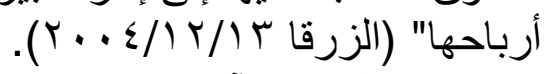

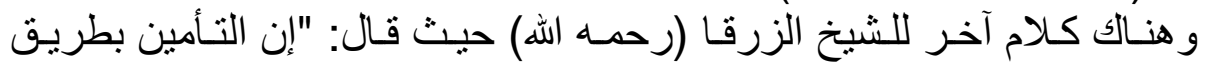

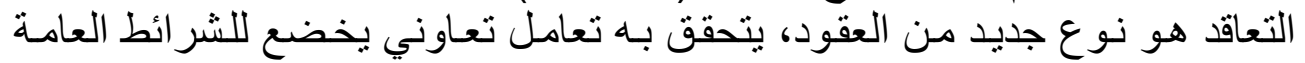

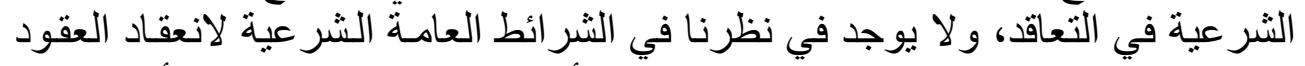

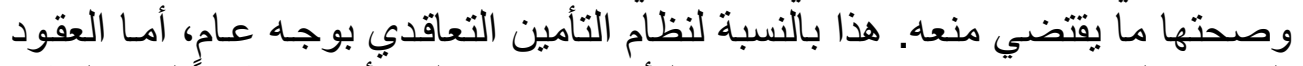

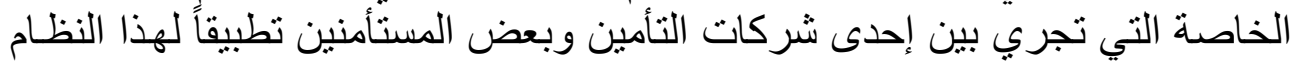

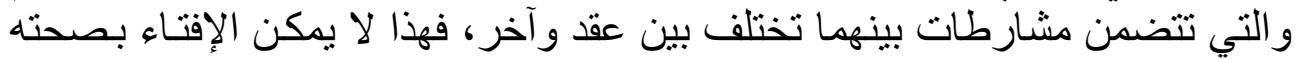

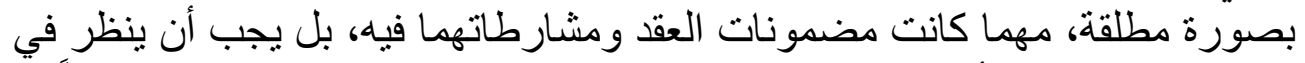

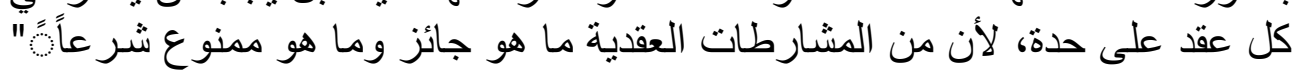

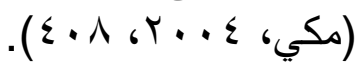

\section{r. بأي الثيخ الدكتور علي جمعة}

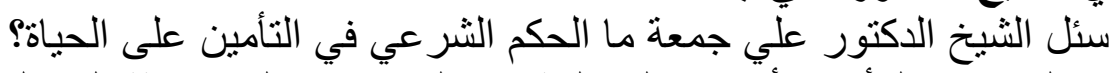

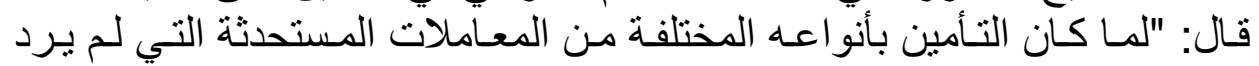

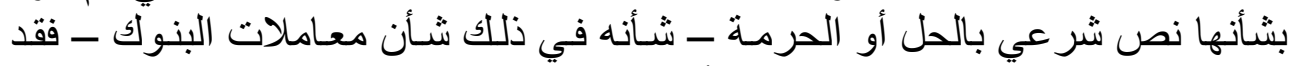

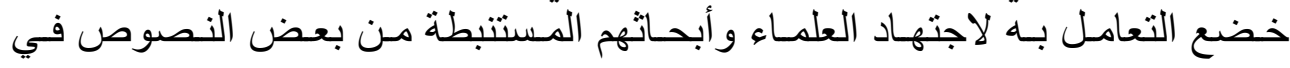




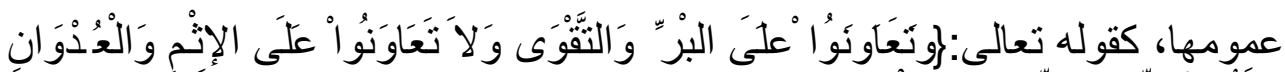

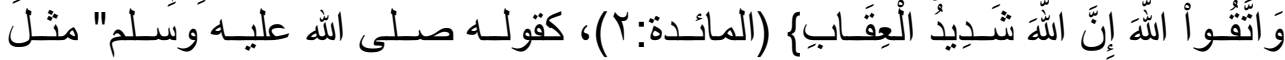

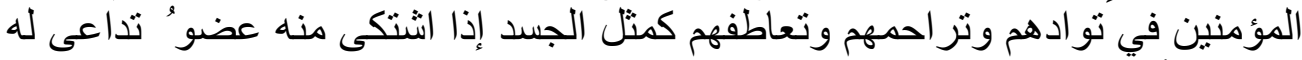

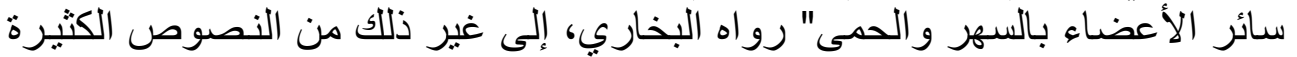

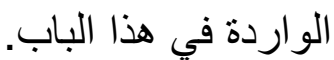

ثالثاً شرعية التأمين التعاوني

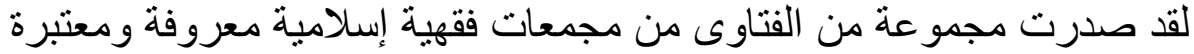

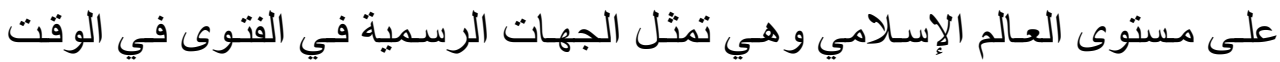

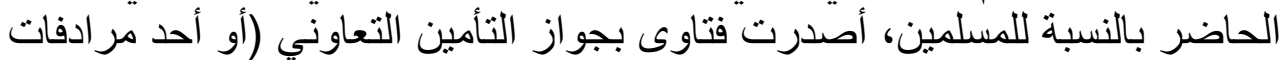

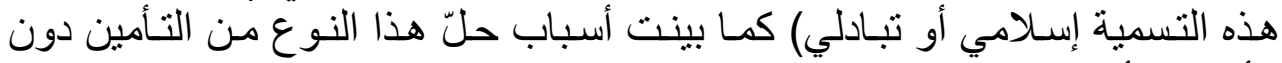

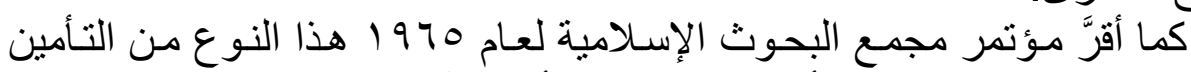

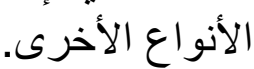

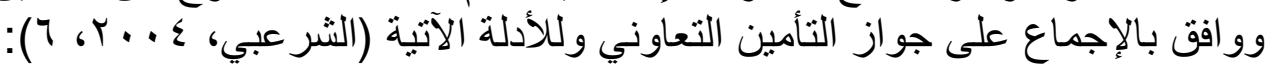

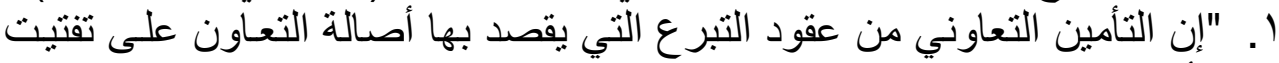

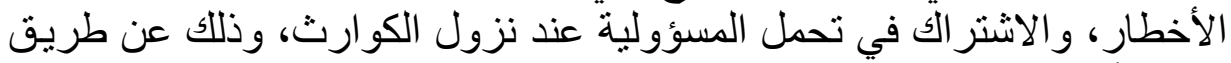

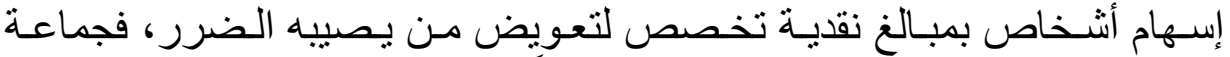

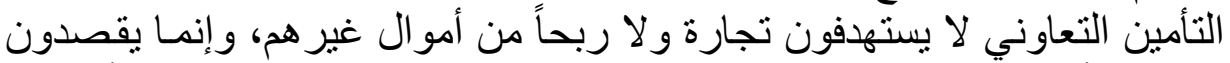

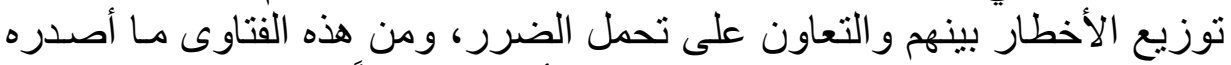

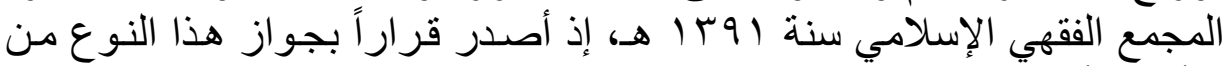

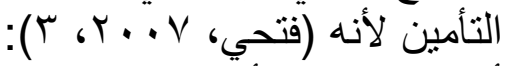
أ. يقوم على مبدأ ألتعاون على البر و التقوى وليس على على المعاوضـة والربح، فلا

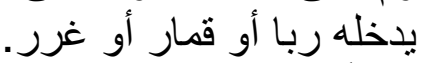

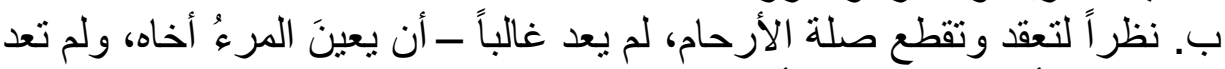

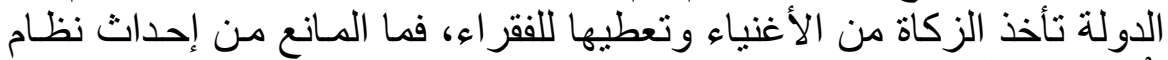

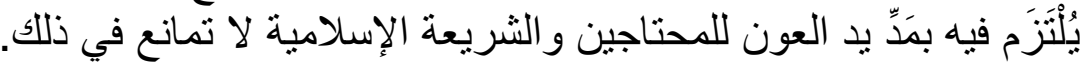

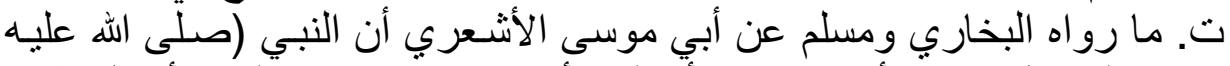

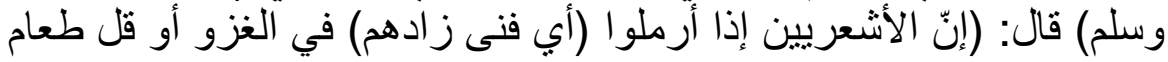

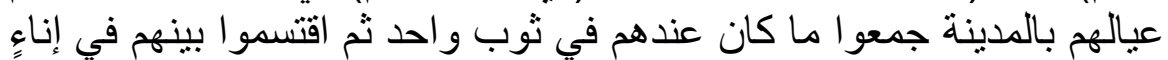

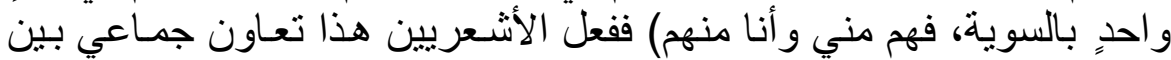

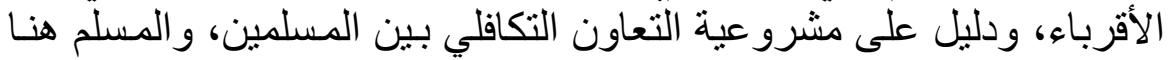

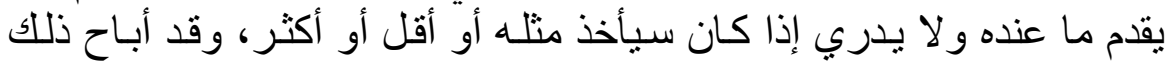
رسول اله (صلى الله عليه وسلم) بقوله في مدح الأشتريين ((فهم مني وأنسا

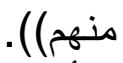

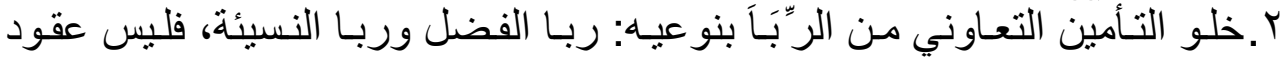

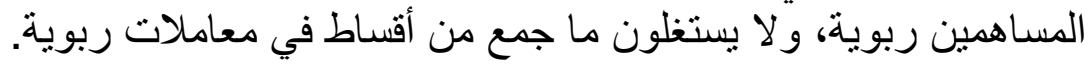




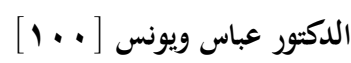

r. لا يضر جهل المساهمين في التأمين التعاوني بتحديد ما يعود عليهم من النفع فهم

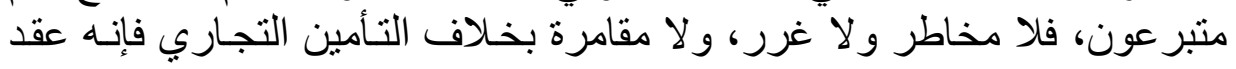
كعاوضة مالية تجارية.

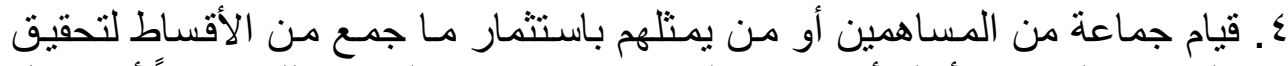

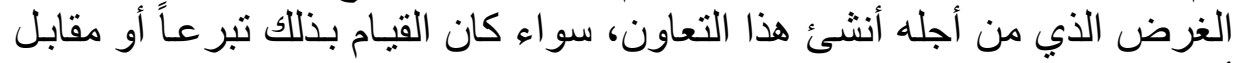
أجر معين.

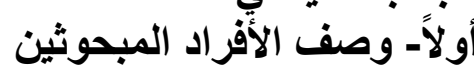
أ. توزيع الأفر اد المبحوثين بحسب الأبن الحالة الاجتماعية

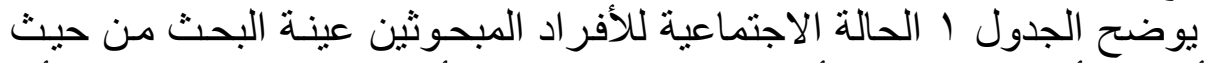

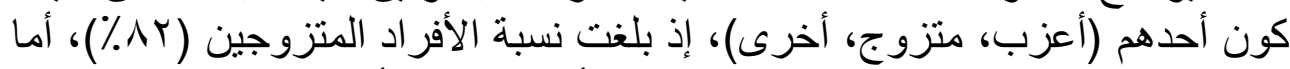

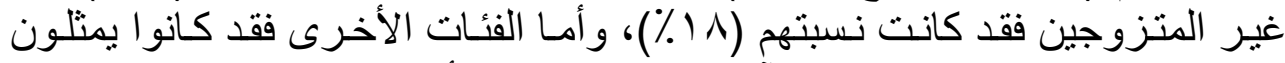

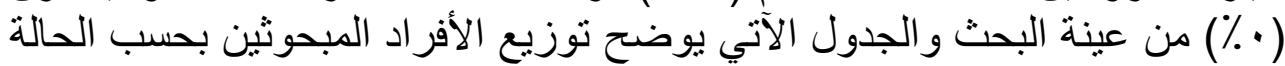

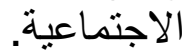

\begin{tabular}{|c|c|c|}
\hline \multicolumn{3}{|c|}{ توزيع الأفراد المبحوثين بحسب الحالة الاجتماعية } \\
\hline النسبة المئوية & التكرار & الجنس \\
\hline 11 & 7 & أعزب \\
\hline$\overline{A r}$ & $r \wedge$ & متزوج \\
\hline صفر & صفر & أخرى \\
\hline $1 \ldots$ & $\Gamma \varepsilon$ & المجموع \\
\hline
\end{tabular}

ب. توزيع الأفراد المبحوثين بحسب الفئات العمرية

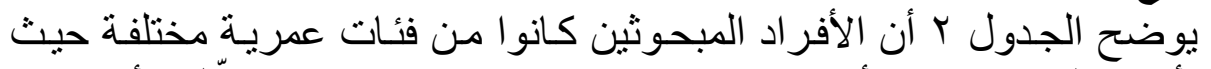

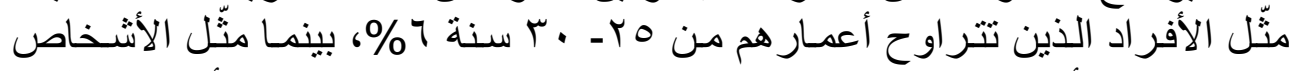

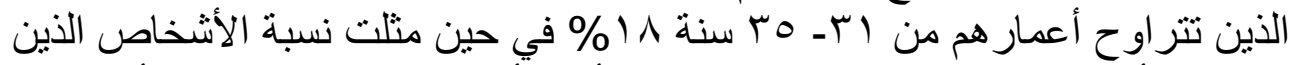

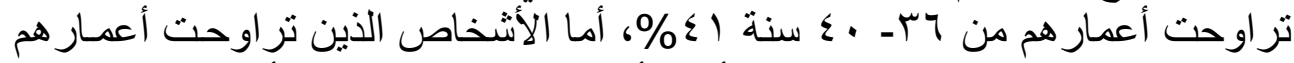

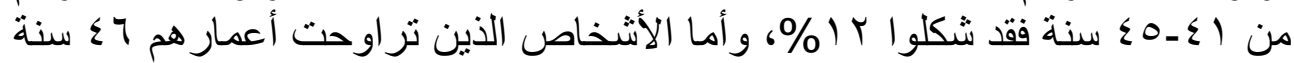

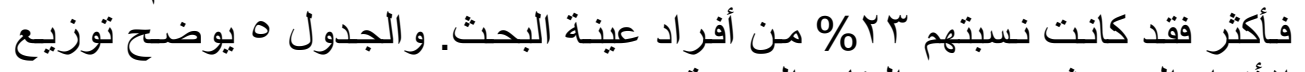
الأفر اد المبحوثين بحسب الفئات العمرية.

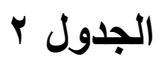

توزيع الأفراد المبحوثين بحسب الفئات العمرية

الفئات العمرية




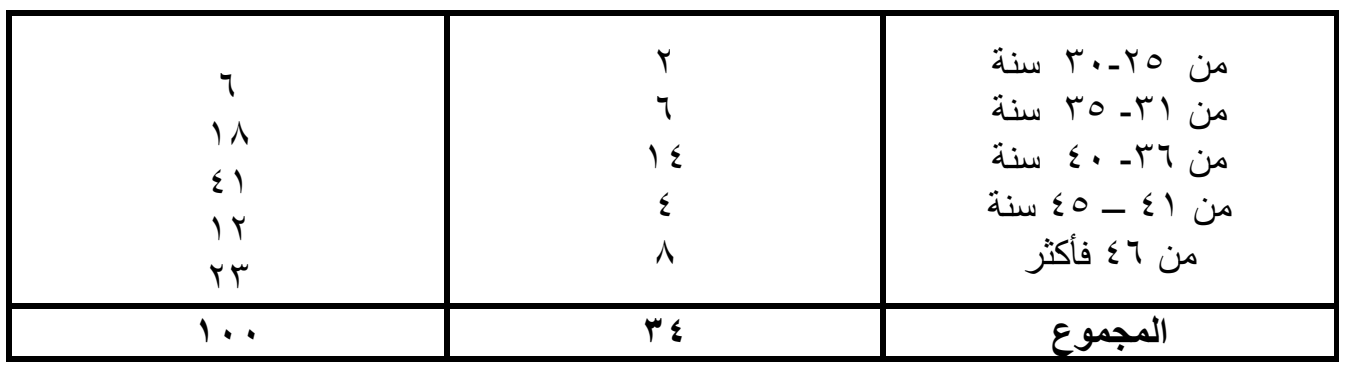

جـ ـ توزيع الأفراد المبحوثين على وفق التحصيل العلمي

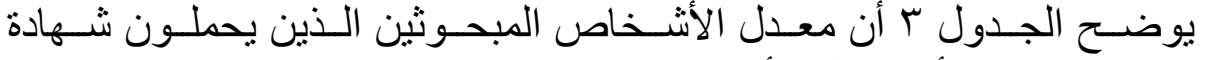

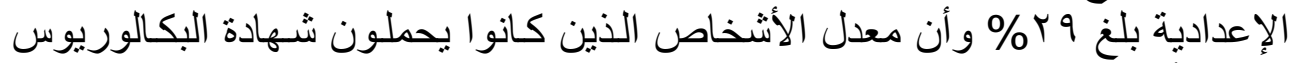

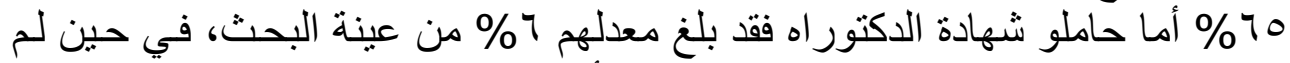

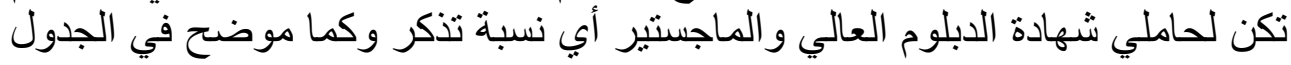

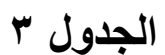

\begin{tabular}{|c|c|c|}
\hline النسبة المئوية & التكرار & التحصيل الاراسي \\
\hline $\begin{array}{l}7 \\
1 \\
1 \\
10 \\
\text { r9 }\end{array}$ & $\begin{array}{l}r \\
\text { صفر } \\
r \text { r } \\
1 .\end{array}$ & دكتور داهتير \\
\hline $1 \ldots$ & $r \varepsilon$ & المجموع \\
\hline
\end{tabular}

د. توزيع أفراد العينة بحسب التخصص الثرعي الدقيق

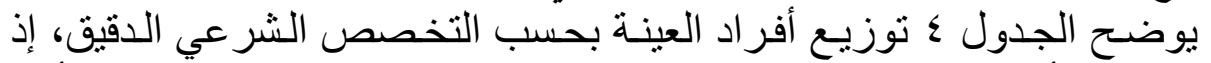

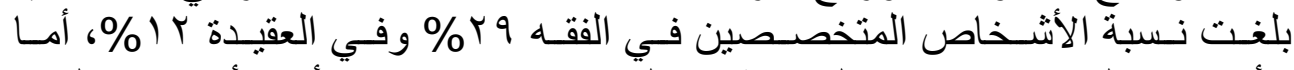

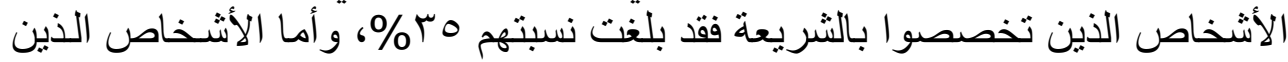
تخصصو ا في الحديث فقد بلغت نسبتهم ع ب\% من عينة البحث.

\section{الجدول ؛}

توزيع أفراد العينة بحسب التخصص الثرعي الدقيق

\begin{tabular}{|c|c|c|}
\hline النسبة المئوية & التكرار & لتحصيل العلمي \\
\hline 19 & 1 . & الفقه \\
\hline
\end{tabular}


الدكتور عباس ويونس [ץ + []]

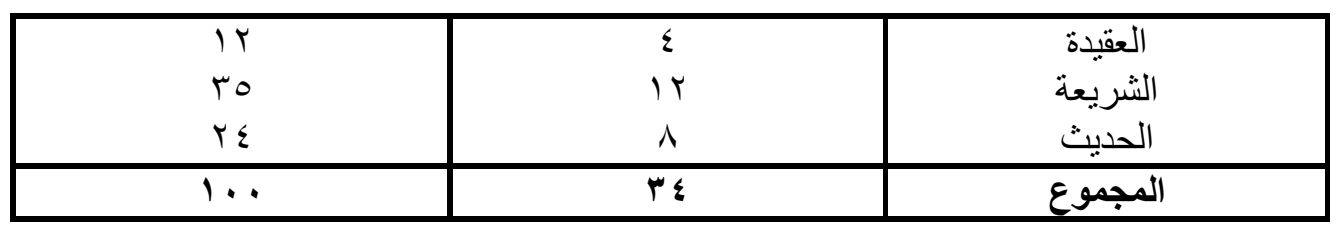

\section{ثثانياً وصف متغيرات البحث وتثخيصها}

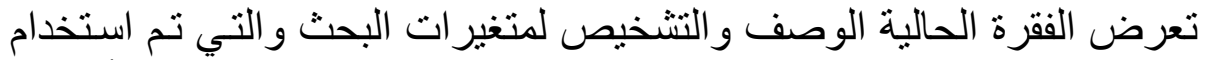

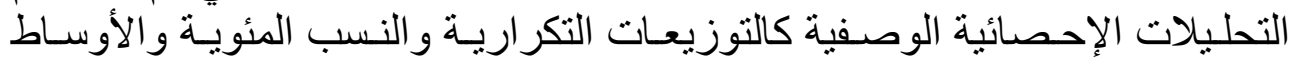

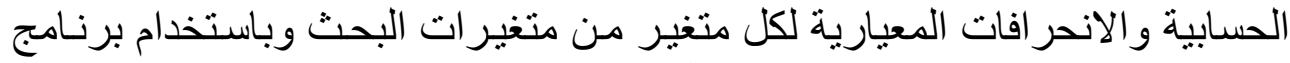

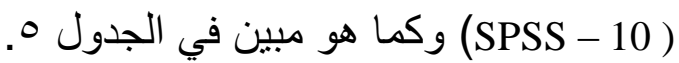

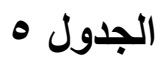

توزيع التكرارات والأوساط الحسابية والانحرافات المعيارية لمتغيرات البحث

\begin{tabular}{|c|c|c|c|c|c|c|c|c|c|c|c|c|}
\hline \multirow{3}{*}{ 高 } & \multirow{3}{*}{$\begin{array}{l}\overline{3} \\
\overline{3} \\
\overline{7} \\
3 \\
3\end{array}$} & \multicolumn{10}{|c|}{ قياس الاستجابة } & \multirow{3}{*}{$\begin{array}{l}3 \\
73 \\
3 \\
5 \\
3 \\
3 \\
3\end{array}$} \\
\hline & & \multicolumn{2}{|c|}{ لا أثفى } & \multicolumn{2}{|c|}{ لا أتقق } & \multicolumn{2}{|c|}{ محايد } & \multicolumn{2}{|c|}{ أتقق } & \multicolumn{2}{|c|}{ أتفق بشدة } & \\
\hline & & $\%$ & ت & $\%$ & ت & $\%$ & ت & $\%$ & 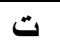 & $\%$ & ث & \\
\hline 1.11 & r. $1 \varepsilon$ & r.r. & 11 & $\varepsilon 1 . r$ & $1 \varepsilon$ & $1 \leq . V$ & 0 & r. 9 & 1 & $\wedge . \wedge$ & $r$ & $\mathrm{X}_{1}$ \\
\hline $1.0 \mathrm{~V}$ & $r .0$ & YT.0 & 9 & 11.1 & $\varepsilon$ & $1 V .7$ & 7 & $1 V .7$ & 7 & YT.O & 9 & $\mathrm{X}_{2}$ \\
\hline $1 . r V$ & T.TV & $\Lambda . \wedge$ & $r$ & 11.1 & $\varepsilon$ & 11.1 & $\varepsilon$ & rᄉ. & Tr & rq. & 1. & $X_{3}$ \\
\hline $1 . V$ & $\varepsilon$ & r. 9 & 1 & $\Lambda . \wedge$ & $r$ & $11 . \wedge$ & $\varepsilon$ & r৯.r & $\pi$ & $r \Lambda \cdot r$ & $\pi$ & $\mathrm{X}_{4}$ \\
\hline $1 . r V$ & $\varepsilon . Y .0$ & 11.1 & $\varepsilon$ & $*$ & $*$ & $*$ & $*$ & T. & 11 & 00.9 & 19 & $\mathrm{X}_{5}$ \\
\hline.$\leqslant 7$ & $\varepsilon . V$. & $*$ & $*$ & $*$ & * & $*$ & $*$ & rq. & 1 & $V \cdot .7$ & $r \varepsilon$ & $\mathrm{X}_{6}$ \\
\hline$\therefore \wedge \varepsilon$ & $\varepsilon .10$ & $*$ & $*$ & 0.9 & $r$ & 0.9 & $r$ & ro.r & 14 & or. 9 & 11 & $\mathrm{X}_{7}$ \\
\hline .77 & $\varepsilon .00$ & $*$ & $*$ & $*$ & $*$ & $\wedge . \wedge$ & $r$ & YT.0 & 9 & $7 \leq . V$ & Yr & $\mathrm{X}_{8}$ \\
\hline $.0 Y$ & $\varepsilon . V$. & $*$ & $*$ & * & $*$ & r. 9 & 1 & YT.0 & $\Lambda$ & $V T .0$ & ro & $\mathrm{X}_{9}$ \\
\hline.$\wedge \wedge$ & $\varepsilon . \Gamma \wedge$ & $*$ & $*$ & $*$ & * & YT.0 & 9 & $\Lambda . \wedge$ & $r$ & $7 \leqslant . V$ & Yr & $\mathrm{X}_{10}$ \\
\hline 1.1 & r.9 & $*$ & $*$ & r. 9 & 1 & $\varepsilon \varepsilon .1$ & 1. & $\Lambda . \wedge$ & $r$ & $\varepsilon \varepsilon .1$ & 10 & $\mathrm{X}_{11}$ \\
\hline 1.19 & $r . \leqslant 1$ & $\Lambda . \wedge$ & $r$ & 18.7 & 7 & ro.r & Ir & * & * & rᄉ. r & $1 T$ & $\mathrm{X}_{12}$ \\
\hline 1.50 & Y. $9 \leq$ & $\Lambda . \Lambda$ & $r$ & ro.r & 14 & 57.0 & 9 & 11.1 & $\varepsilon$ & 18.7 & 7 & $\mathrm{X}_{13}$ \\
\hline سז. & $r .91$ & 18.7 & 7 & $\wedge . \wedge$ & r & 00.9 & 19 & * & * & 18.7 & 7 & $\mathrm{X}_{14}$ \\
\hline 1.50 & $r .0$ & $\Lambda . \Lambda$ & $r$ & rq. & 1. & r7.0 & 9 & 18.7 & 7 & 18.7 & 7 & $\mathrm{X}_{15}$ \\
\hline 1.71 & $Y . \leq \varepsilon$ & $\varepsilon \varepsilon .1$ & 10 & 18.7 & 7 & $\wedge . \wedge$ & $r$ & $\Lambda . \wedge$ & $r$ & $r . .7$ & 7 & $\mathrm{X}_{16}$ \\
\hline $1 . V Y$ & $1 . V$. & $0 \wedge .1$ & $r \cdot$ & 11.1 & $\varepsilon$ & rq. & $1 \cdot$ & * & * & * & * & $\mathrm{X}_{17}$ \\
\hline $1 . r V$ & r.OT & $\Lambda . \wedge$ & $r$ & 18.7 & 7 & $r \cdot .7$ & $V$ & 18.7 & 7 & ro.r & 14 & $\mathrm{X}_{18}$ \\
\hline
\end{tabular}




\begin{tabular}{|c|c|c|c|c|c|c|c|c|c|c|c|c|}
\hline \multirow{3}{*}{$\begin{array}{l}\bar{y} \\
\overline{3} \\
\bar{y} \\
\bar{y}\end{array}$} & \multirow{3}{*}{$\begin{array}{l}\overline{\bar{\alpha}} \\
\overline{3} \\
\overline{\bar{j}} \\
3 \\
\mathbf{3}\end{array}$} & \multicolumn{10}{|c|}{ قياس الاستجابة } & \multirow{3}{*}{ 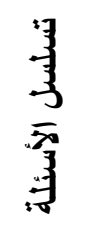 } \\
\hline & & \multicolumn{2}{|c|}{ لا بشدة أتفق } & \multicolumn{2}{|c|}{ لا أتفق } & \multicolumn{2}{|c|}{ محايد } & \multicolumn{2}{|c|}{ أتفق } & \multicolumn{2}{|c|}{ أتفق بثدة } & \\
\hline & & $\%$ & ت & $\%$ & ت & $\%$ & ت & $\%$ & ت & $\%$ & $ت$ & \\
\hline 1.19 & $r_{.} \cdot r$ & r. & 9 & 00.9 & 19 & $\Lambda . \wedge$ & $r$ & 0.9 & $r$ & r. 9 & 1 & $\overline{X_{19}}$ \\
\hline$\cdot .94$ & $\varepsilon . \mu \Lambda$ & 7.9 & 1 & r. & 1 & r.9 & 1 & ro.r & Tr & 00.9 & 19 & $\overline{X_{20}}$ \\
\hline \multirow{2}{*}{1.11} & \multirow{2}{*}{ r.0. } & \multirow{2}{*}{\multicolumn{4}{|c|}{\begin{tabular}{l|l}
$1 r .9 r$ & $1 r .97$ \\
$r 7.19$
\end{tabular}}} & \multirow{2}{*}{\multicolumn{2}{|c|}{ IV.Vo }} & IV. & & Tr & & المؤشر \\
\hline & & & & & & & & \multicolumn{4}{|c|}{01.11} & الكلي \\
\hline
\end{tabular}

تشير معطيات الجدول ه و الخاصة بالتوزيعات التكر اريـة و الأوساط الحسابية

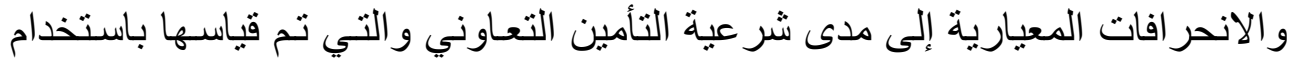

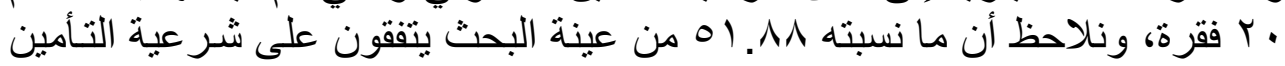

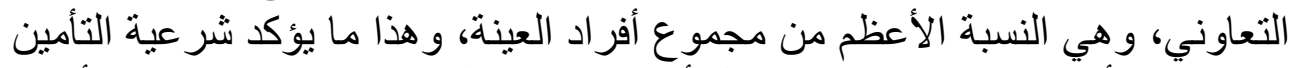

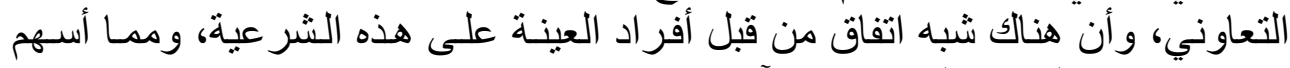
في إغناء هذه النتيجة المتغيرات التهات الآتية:

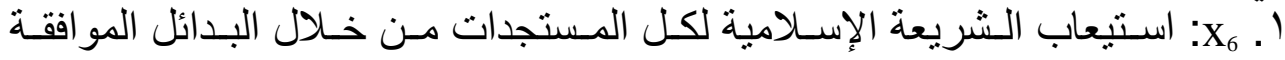

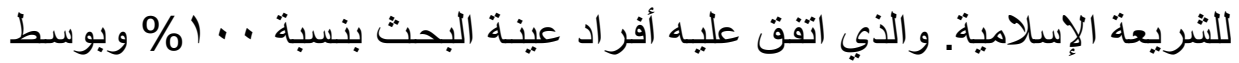

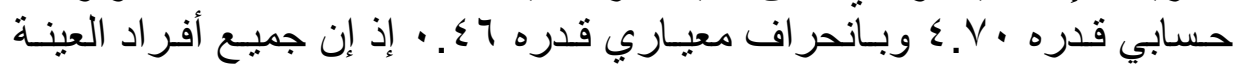

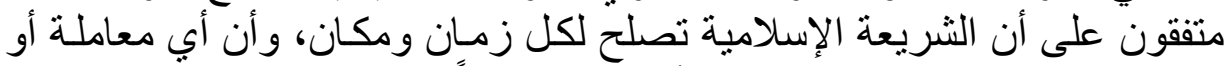

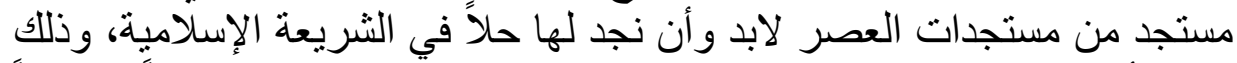

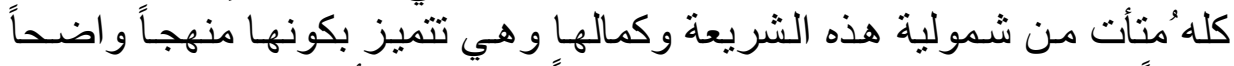

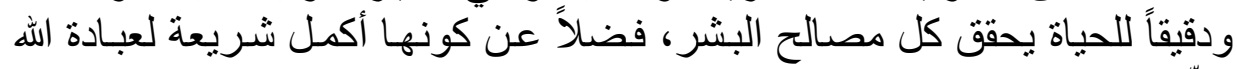

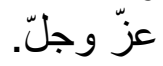

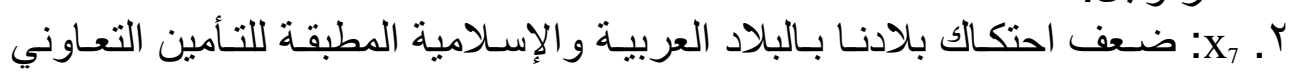

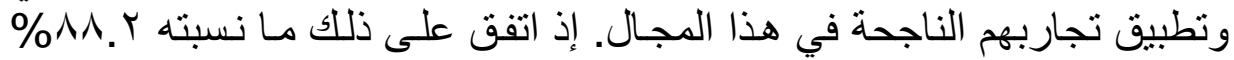

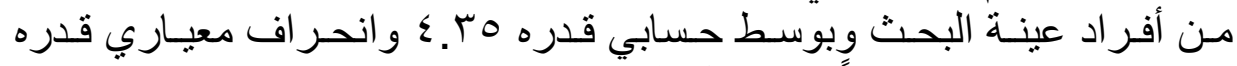

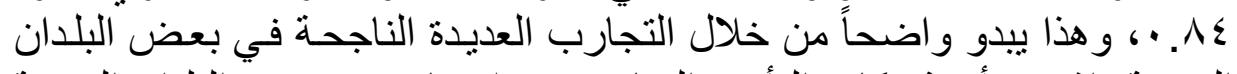

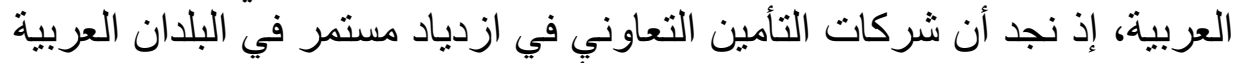

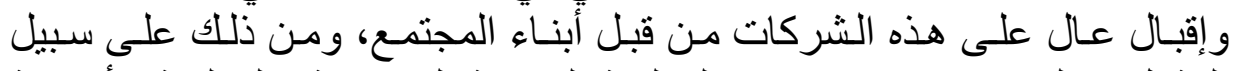

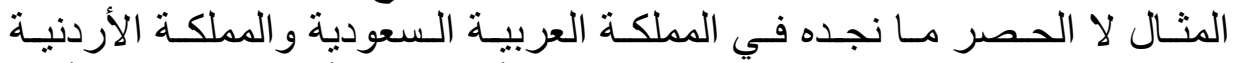

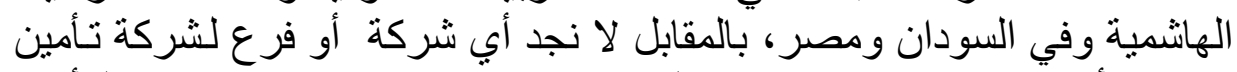

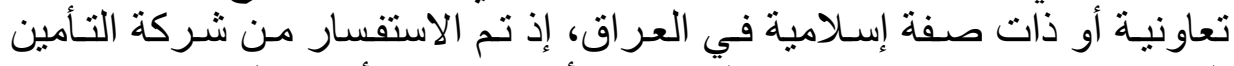

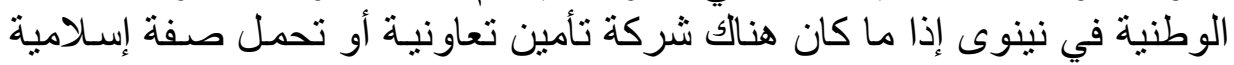

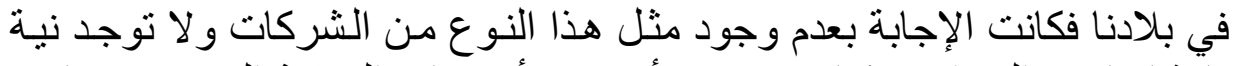

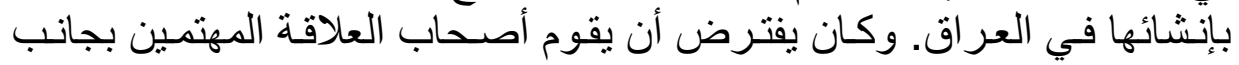


التأمين بمحاولـة نقل تجـارب ناجحة للتأمين التعاوني مطبقة في بعض البلدان

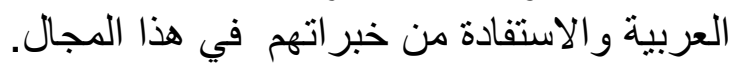

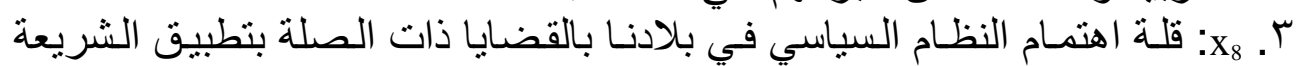

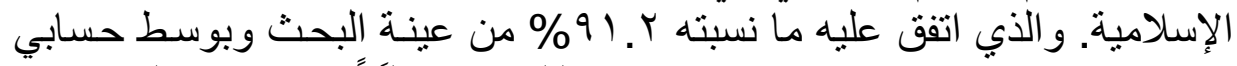

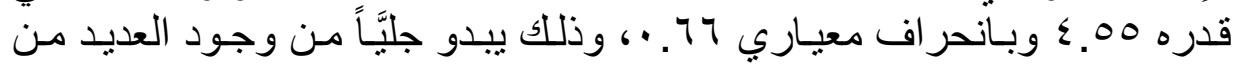

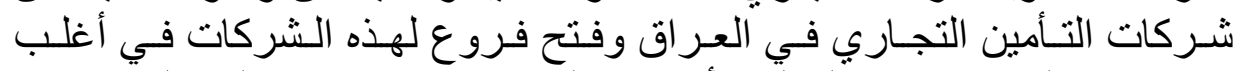

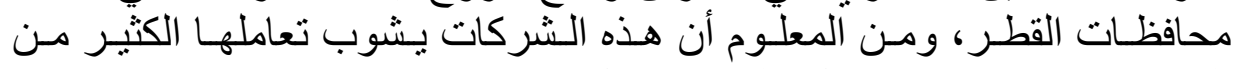

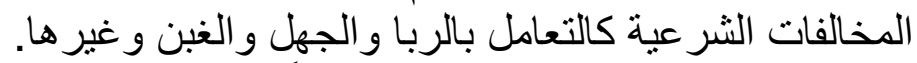

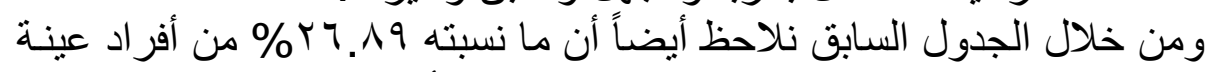

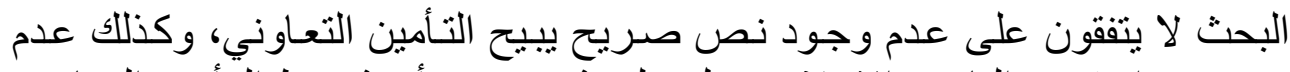

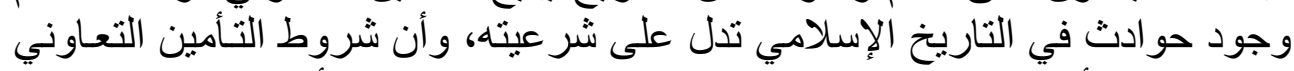

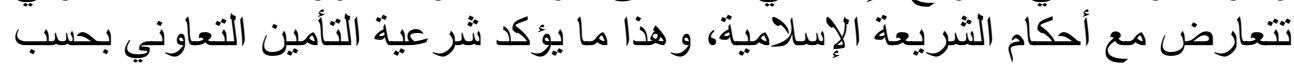

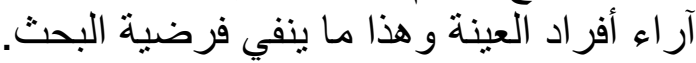

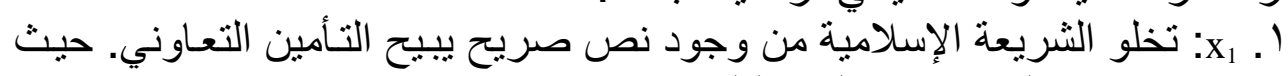

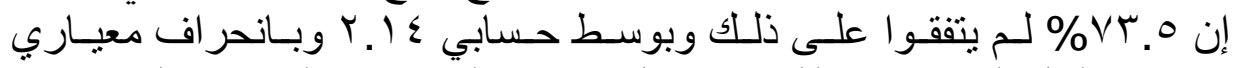

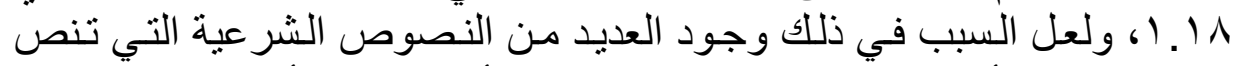

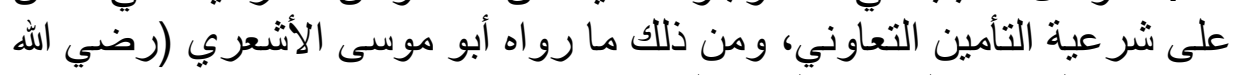
عنه) عن النبي (صلى الله عليه وسلم):

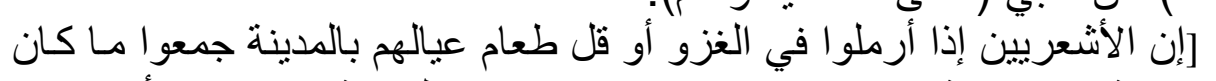

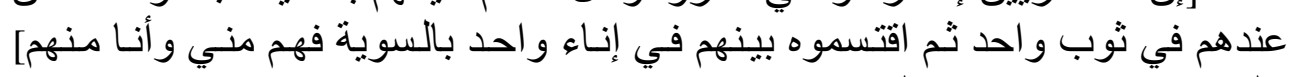

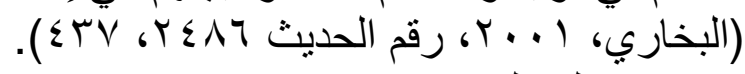

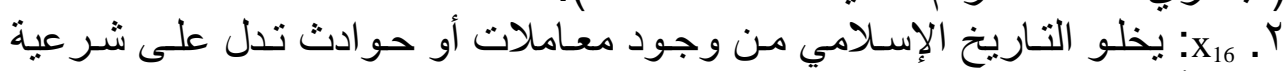

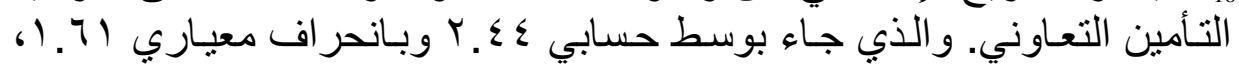

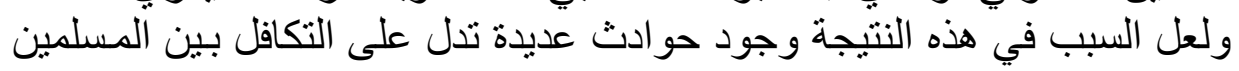

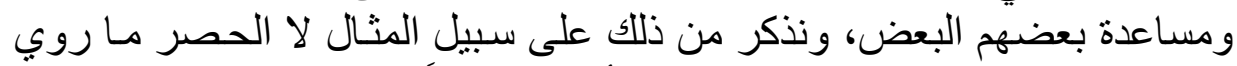

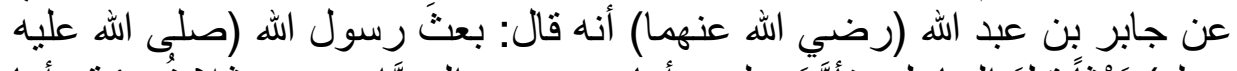

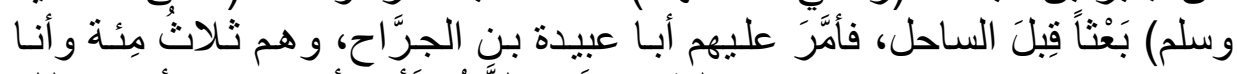

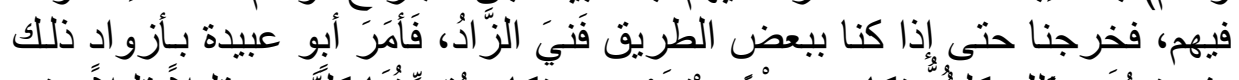

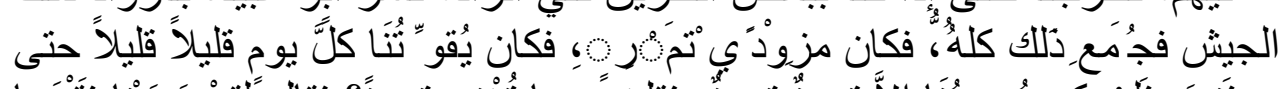

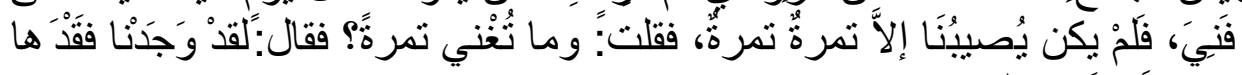

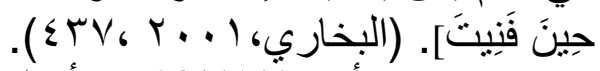

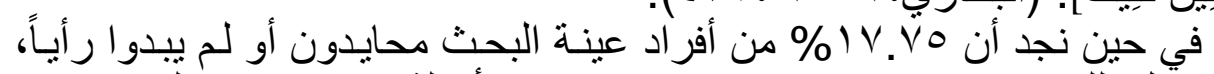

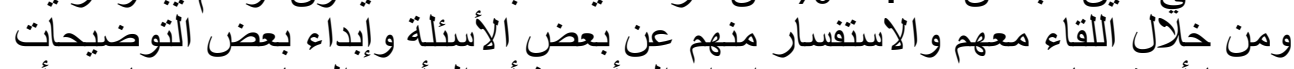

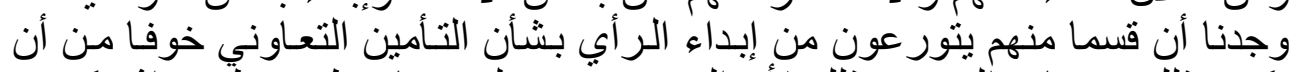

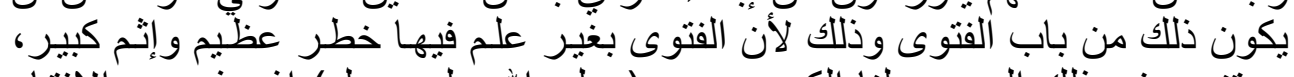

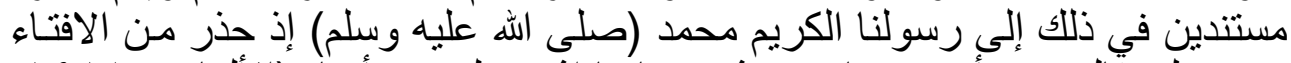

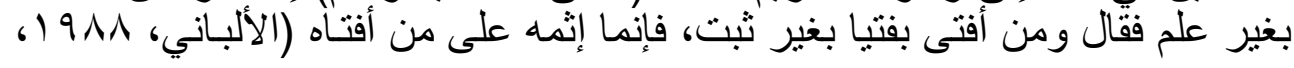




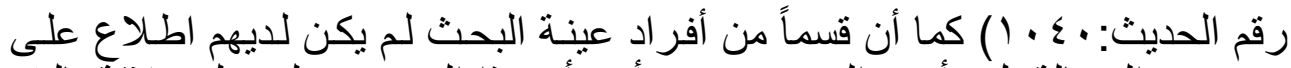

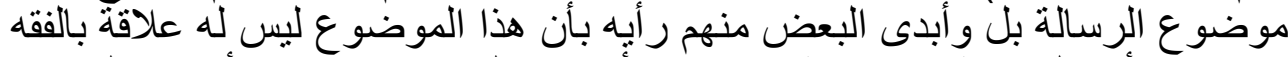

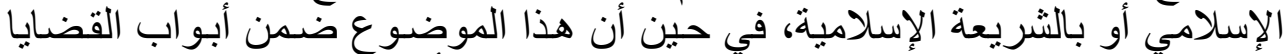

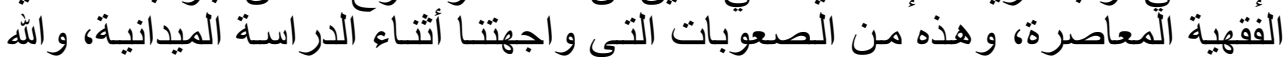

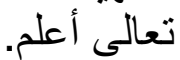

الاستتناجات والمقترحات أولاً - الاستنتاجات المات

ومن خلال النتائج التي توصل إليها البحث ندرج الاستينتاجات الآتية:

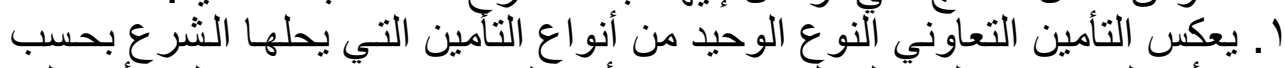

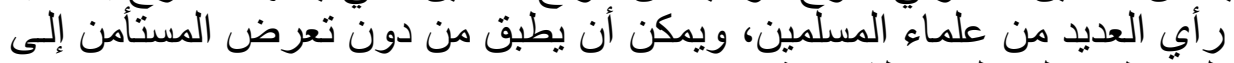

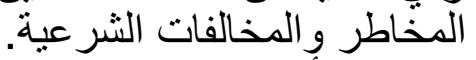

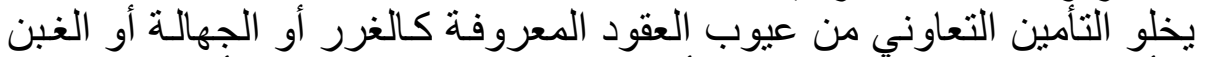

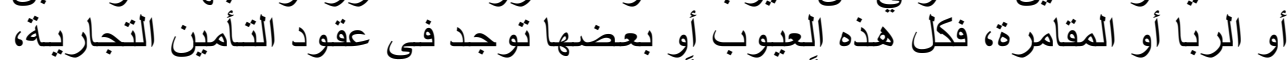

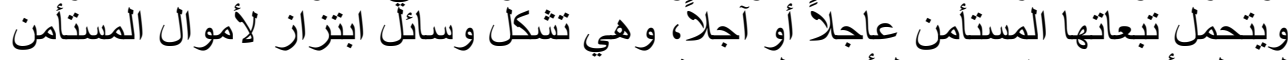

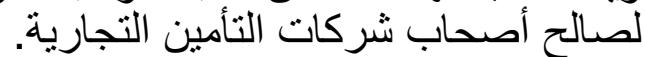

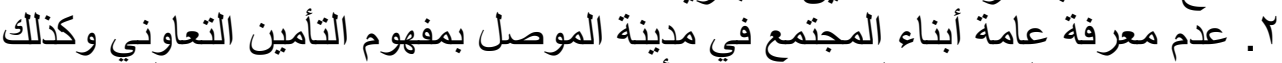

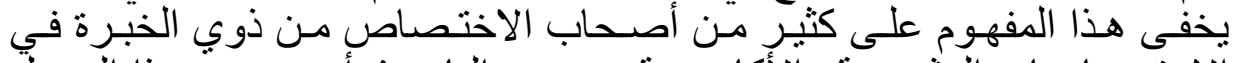

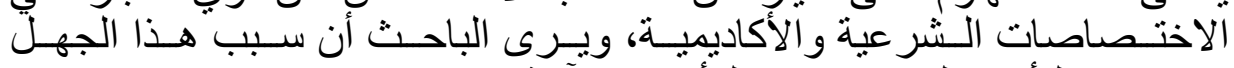
بموضوع التأمين التعاوني يعود للأسباب الآتية:

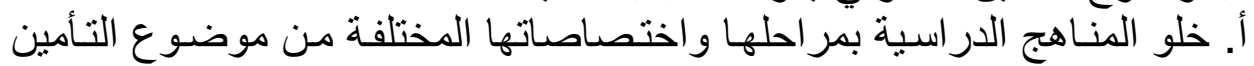

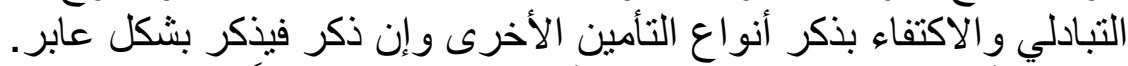

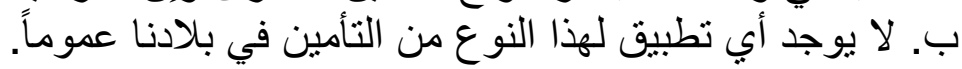

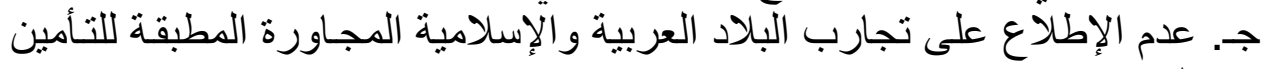

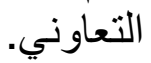
r. يحرم الدين الإسلامي الحنيف أنواع التأمين الأخرى تحريماً قاطعاً لمـا فيها من عيوب عقد التأمين المعروفة. المئ.

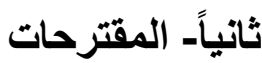

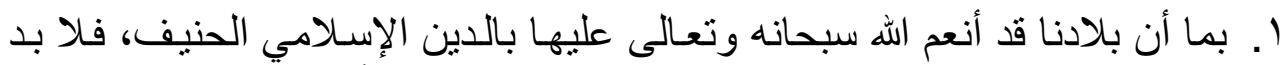

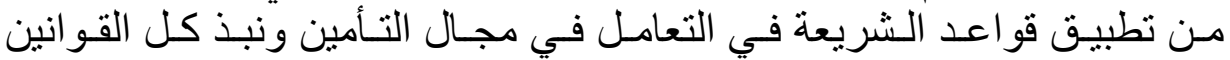

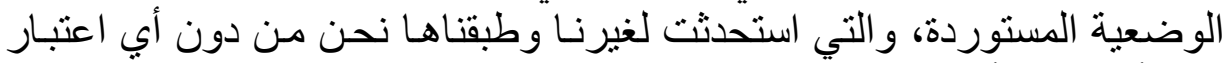

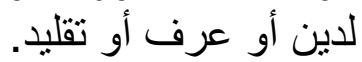

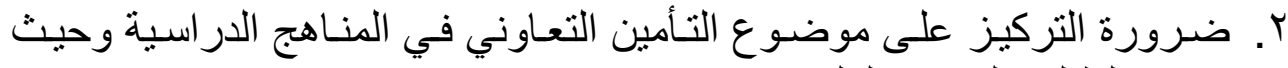

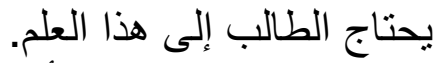

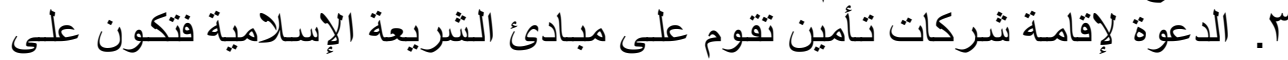

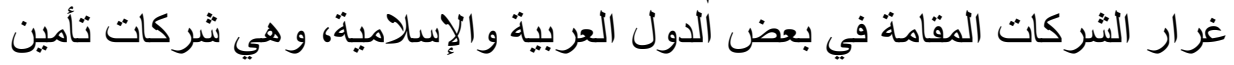




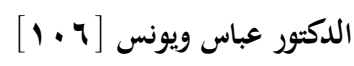

تعاونية (إسلامية) تلبي حاجات المجتمع المسلم، وتبعده عن مداخل الثر ومهاوي الحر ام و اللجوء إلى شركات التئ التأمين التجاري.

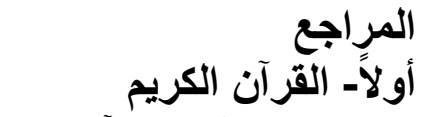

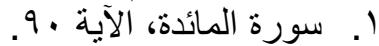

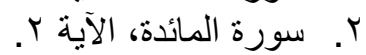

ثانياً- كتب الحديث والسنة النبوية المطهرة

'. الألباني، محمد ناصر الدين، صحيح الجامع و زيادنه، 911 (1، الدكتب الإسلامي، الطبعة

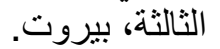

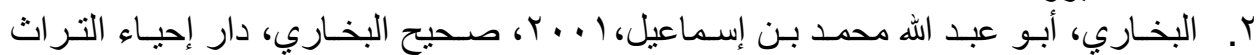

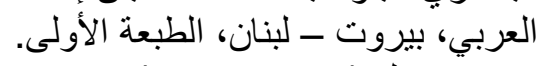

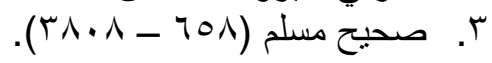

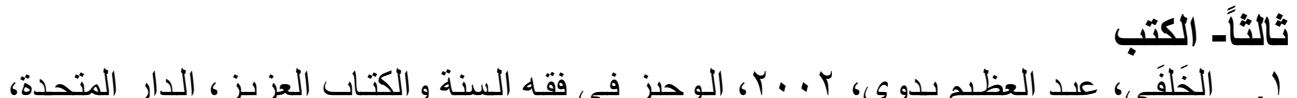

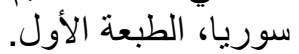

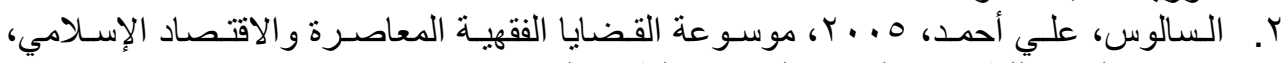
مؤسسة الريان للطباعة والنشر و التوزيع، الطبعة السبابعة.

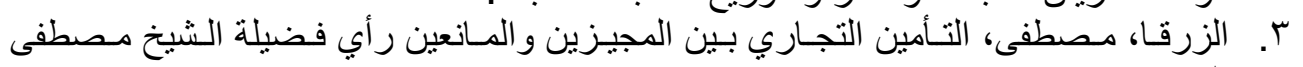

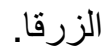

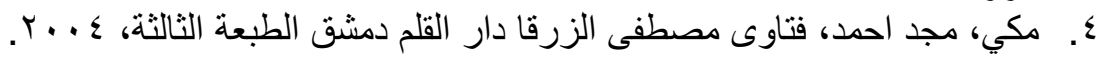
رابعاً- الإنترنت

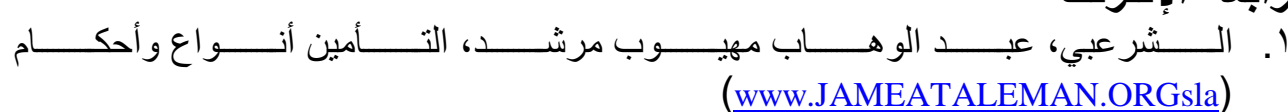
r. فتحي، محمد، الثأمين من منظور إسلامي (www.islamtody.net). 